\title{
Procesos de alteración por causa de la industria patrimonial en úbeda y Baeza
}

\author{
Eugenio Ismael Rodríguez Castillo | arquitecto \\ URL de la contribución <www.iaph.es/revistaph/index.php/revistaph/article/view/4480>
}

\section{Introducción}

El aumento de la actividad turística que reciben los centros históricos especialmente significados desde el punto de vista de su valor patrimonial, en este caso por los conjuntos monumentales renacentistas de Úbeda y Baeza, está teniendo un impacto creciente en el paisaje urbano, provocando procesos de alteración, latentes unos, emergentes otros, que cuando se desencadenan suelen ser intensos, de rápida progresión, amplio calado, y gran poder transformador, incidiendo de manera desigual sobre aspectos formales, socioeconómicos y simbólicos (GARCÍA HERNÁNDEZ; DE LA CALLE VAQUERO; YUBERO, 2017: 14).

\section{Procesos de alteración de la estructura urbana}

En primer lugar actúan provocando desplazamientos de uso y alteraciones funcionales, y sobre la caracterización de los tejidos social y productivo.

Úbeda cuenta con inmuebles relevantes por su valor patrimonial, vinculados a la actividad turística, como el hotel palacio de Úbeda (en el palacio de los Condes de Guadiana), el parador de úbeda (en el palacio del Deán Ortega); al igual que ocurre en Baeza, con el hotel palacio de los Salcedo (en el palacio de los Salcedo o Condes de Garciez), o la oficina de turismo (en la audiencia civil y escribanías públicas).

El uso turístico ya ha producido en Úbeda y Baeza una alteración urbana significativa, en combinación con hábitos muy asentados de ocio y consumo en calles emblemáticas (calle Real en Úbeda, por ejemplo), concentración del uso administrativo (como los ayuntamientos de Úbeda y Baeza) y con las limitaciones espaciales, de accesibilidad y estacionamiento endémicas de los centros históricos de las que también adolecen, redu- ciendo a la mínima expresión, los equipamientos necesarios para el normal desarrollo de la vida urbana actual, que exige una constante movilidad y una amplia oferta de equipamientos y comodidades, alejando paulatinamente a los centros históricos del estándar de prestaciones mínimo deseable para el habitar, deprimiendo y degradando trazas, escenarios y contextos secundarios vulnerables del paisaje urbano de estas áreas tan significadas.

Al tiempo que se transforman los centros históricos orientándolos progresivamente al uso turístico, se distancian también las percepciones y valoraciones del paisaje urbano por parte de los residentes (en términos de calidad de vida; de carácter no permanente, pero casi); y por parte de los visitantes (en términos de calidad de la oferta turística; de carácter temporal, limitado a la estancia).

Mientras que el uso administrativo profundiza en la vinculación simbólica del patrimonio con el poder, el uso turístico y los hábitos de ocio y consumo de masas banalizan y empobrecen el paisaje urbano, al tiempo que lo transforman en un estándar reconocible, y envuelven la riqueza patrimonial en un banco de niebla que tiende a homogeneizar el paisaje urbano.

Las ciudades patrimonio que sufren este fenómeno de turistificación experimentan una conversión comercial y productiva: acuden seducidas las grandes marcas globales y se van orientando progresivamente las actividades comerciales al turismo, ofreciendo con el tiempo un paisaje estandarizado, con pérdida de autenticidad y un deterioro en su percepción progresivo y tendente al estereotipo, que es un proceso vastamente explorado de consecuencias conocidas que exige anticipar medidas preventivas-adaptativas y trabajar una adecuada resiliencia. 
Un ejemplo es la reciente proliferación de marcas globales de comida rápida en la Úbeda periférica, en plena progresión competitiva de una potente restauración local de altísima calidad, y del turismo gastronómico asociado. De manera superpuesta, se produce un fenómeno de sustitución gradual del comercio local y de proximidad orientado al residente, por otro orientado al turista, o al ocio y al consumo. La mayor expectativa de negocio y la limitación en la oferta de locales bien situados genera un fenómeno inflacionista que repercute necesariamente, entendida también en términos de oportunidad, sobre los productos y servicios turísticos que otro tipo de actividades no podrían justificar; y también sobre soluciones de reconversión de uso al alojamiento turístico con la consecuente y progresiva gentrificación.

En consecuencia, se produce una alteración gradual y difícil de revertir de usos y funciones en estas áreas significadas, al tiempo que se profundiza en la escasez de bienes y servicios de proximidad orientados al residente con su traslación forzosa a otras áreas menos competidas, desplazando igualmente el uso residencial, y promoviendo la sustitución de usos y funciones orientadas al residente por otras orientadas al turismo, en un proceso que se retroalimenta.

A pesar de estos efectos, las cifras económicas vinculadas al desarrollo de los sectores patrimonial y turístico, de la hostelería, el comercio, el ocio y la restauración, suponen un agregado con una incidencia muy positiva desde un punto de vista socioeconómico en las comunidades locales de Úbeda y Baeza, diversificando sus insumos, excesivamente dependientes de la agricultura y sus ciclos económicos; y son fuente de desarrollo, activando los resortes que permiten explotar el capital cultural como activo turístico, al tiempo que genera los recursos para garantizar su salvaguarda y protección.

\section{Procesos de alteración de la estructura cultural}

Por último, actúan también sobre la autenticidad, la percepción, la singularidad cultural y el carácter simbólico. La supervivencia de la tradición se dirime en gran medida en estos centros históricos donde se concen- tran, cultivan y manifiestan las expresiones de las tradiciones y el folclore.

La autenticidad de los valores que la comunidad en su conjunto ha identificado como propios y considerado como dignos de preservar y transmitir se ve también amenazada por su inclusión en circuitos turísticos que retroalimentan su banalización y distorsión histórica (como las fiestas del Renacimiento), por el estrés urbano derivado de la actividad turística y por adoptar: por un lado, una agenda cultural cada vez más popular y con poco margen para la cultura independiente y de producción local; por otro, soluciones impropias y estandarizadas a problemas comunes, alterando la percepción del paisaje patrimonial (tren turístico, mobiliario urbano de diseño, alumbrado público).

El patrimonio cultural se entiende como "un sector estratégico y de oportunidad" (CARTA, 2009); incorporada ya la vertiente turística, la industria patrimonial en su conjunto propende a expandirse y a protegerse, haciendo más compleja la conciliación de intereses y obligando a profundizar en la sostenibilidad de un modelo de producción y consumo turístico, que es necesario transformar (PULIDO FERNÁNDEZ; PULIDO FERNÁNDEZ, 2015: 1329).

\section{BIBLIOGRAFÍA}

- CARTA de Bruselas sobre el papel del Patrimonio Cultural en la economía, y para la creación de una red europea de su reconocimiento y difusión. Bruselas, a 30 de junio de $2009<$ <ttps://www.jcyl.es/web/jcyl/binarios/523/935/carta de Bruselas,0.pdf $>$ [Consulta: 02/07/2019]

- PULIDO FERNÁNDEZ, J. I.; PULIDO FERNÁNDEZ, M. DE LA C. (2015) ¿Sigue vigente el paradigma del turismo sostenible? Reflexiones a la luz de la literatura reciente. Pasos: Revista de Turismo y Patrimonio Cultural, vol. 13, n. ${ }^{\circ}$ 6, pp. 1315-1335 <https://doi.org/10.25145/j.pasos.2015.13.092> [Consulta: 03/07/19]

- GARCÍA HERNÁNDEZ, M.; DE LA CALLE VAQUERO, M.; YUBERO, C. (2017) Cultural Heritage and Urban Tourism: Historic City Centres under Pressure. Sustainability, 9, 1346 <https://www.mdpi.com/2071-1050/9/8/1346/pdf> [Consulta: 04/07/19] 